\title{
In Memoriam: Javier Hernández-Pacheco In Memoriam: Javier Hernández-Pacheco
}

RESUMEN: En este artículo se presenta la obra sobre Hegel de Javier Hernández Pacheco desde sus primeros escritos hasta hasta sus últimas obras.

PALABRAS CLAVE: JAVIER HERNÁNDEZPACHECO; HEGEL
ABSTRACT: This paper presents Javier Hernández Pacheco's work on Hegel from his earliest writings to his latest works.

KEY WORDS: JAVIER HERNÁNDEZPACHECO; HEGEL

$\mathrm{E}^{\mathrm{l}}$

día 17 de noviembre de 2020 falleció Javier Hernández-Pacheco Sanz, catedrático de Filosofía de la Universidad de Sevilla (1953-2020). Su figura como investigador y profesor ha sido decisiva para muchos de sus estudiantes, amigos y admiradores. Baste con que se lean unas cuantas líneas de cualquier escrito del profesor Hernández-Pacheco para percatarse de cuánto disfrutaba filosofando. Sin duda alguna, su amabilidad y su audaz temple teórico ha sido fuente de inspiración para muchos intelectuales españoles. Y que todavía, durante años, le guardarán en su memoria como figura a seguir.

La historia del profesor Hernández-Pacheco comienza con su nacimiento en Madrid en 1953. Tras el estudio del bachillerato, decidió estudiar Filosofía y Letras en la Universidad Complutense de Madrid entre 1970 y 1975. En solamente once años desde que acabó esta etapa, Hernández-Pacheco llegaría a una de las cimas más altas de la intelectualidad española —insisto, en tiempo récord. Tras acabar sus estudios en la Universidad Complutense de Madrid comenzó su tesis dirigida por Antonio Millán-Puelles, titulada Acto y substancia. Estudio a través de Sto. Tomás de Aquino, tesis que terminaría en 1980. A la par 
que realizaba la tesis para el grado de doctor, estudiaba Filosofía, Pedagogía e Historia en la Universidad de Viena, entre 1977 y 1981. Entre 1980 y 1981 fue becario postdoctoral del PNFPI en la Universidad de Viena. Como decíamos, en esta misma universidad obtuvo también un nuevo grado de doctor con una disertación sobre Martin Heidegger bajo la dirección del profesor Johann Mader en 1982. Esta disertación daría lugar un año más tarde a su obra Die Auflösung des Seins. Die Entwicklung einer phänomenologischen Ontologie im Denken Martin Heideggers, publicada por el servicio de publicaciones de la Universidad de Viena.

Estando en Viena conseguiría una Beca del Plan de Reinserción de Personal Investigador en el Extranjero entre 1981 y 1982, lo que le posibilitó volver a España, concretamente, a la Universidad de Sevilla. Un año más tarde obtendría la plaza de profesor agregado interino, y entre 1983 y 1986 sería profesor adjunto de antropología. En 1986 cuando, con sólo treinta y tres años, consigue la Cátedra de Filosofía. Su recorrido como académico español fue todavía más amplio, pues sería Visiting Scholar de algunas universidades de sumo prestigio, como la de Columbia en Nueva York, en el MIT, en Cambridge, en la Northwestern University de Evanston, y de la Universidad de Oxford en Reino Unido.

En general, su recorrido intelectual, sin duda alguna, siempre estuvo marcado por la metafísica, pero también por la antropología y la teología. Su interés y aportación al estudio sobre Hegel comenzaría también muy temprano. En 1983 publicaría «Diálogo y dialéctica. En torno al problema de la alteridad en G. W. F. Hegel». En relación con la noción de belleza, en discusión con otros autores, entre los que aparecen menciones explícitas a Hegel, también publicaría «Lo bello, lo gustoso, lo difícil». Discutiría también sobre la noción de libertad de Schelling, sin olvidarse de Hegel en «Die Freiheitsleidenschaft bei Schelling». Aunque parezca sorprendente, Hegel seguiría siendo una cuestión acuciante en su publicación «El velo de Isis. Elementos para una mariología romántica» en 1992. Y también, sobre todo en un acercamiento muy directo con Hegel, en su escrito «Fe y reflexión», en el que Hernández-Pacheco nos permitía entrever su posición como creyente y, además, la manera en la que veía la cuestión de la religión en Hegel:

«De igual modo, pienso, con filósofos como Hegel, que la gran tradición judeocristiana en absoluto es incompatible con las exigencias de una equilibrada ilustración; antes bien sostengo, siguiendo también a Hegel, que se da una esencial continuidad entre ambas. El carácter limitado de nuestra reflexión hace que nuestra adhesión a lo que consideramos cierto esté abierta a tradiciones, autoridades, 
vivencias y mociones, de las que no podemos dar cuenta y que no encuentran su justificación en nuestra reflexión explícita». ${ }^{1}$

Su forma de escribir, siempre fue clara y sencilla - lo que es altamente complejo en filosofía-, y a lo largo de algunos años adquirirá también un carácter simpático y muy amigable con su lector. Ofreció reflexiones sobre el cine, el cielo, el medio ambiente... Era una persona que estaba dándose mucho espacio para la reflexión personal. En este periodo nos deja una pequeña joya que ha pasado inadvertida para muchos de los hegelianos españoles que se dediquen a la religión, la política y la historia. Con una interpretación abierta sobre Hegel, el profesor Hernández-Pacheco redactó en un escrito llamado «Cristianismo y Secularización. Reflexiones sobre unos textos de G. W. F. Hegel». Además, en 2010 escribió acerca del círculo de Jena, deteniéndose en la Fenomenología del espíritu. Se trata de un estupendo texto para cualquiera que quiera contextualizar y entender las discusiones que surgían en el periodo del Romanticismo.

En la última década, encontramos probablemente, la culminación de su conocimiento sobre el filósofo nacido en Stuttgart. En primer lugar, en su escrito («Intelecto agente, forma formarum, libertad. De Aristóteles a Hegel, y vuelta a Tomás de Aquino») en homenaje al profesor Leonardo Polo. En este, el catedrático de la Universidad de Sevilla entra en cuestiones epistemológicas y metafísicas comunes a estos tres autores. También tratará la influencia de Hegel en otros autores muy cercanos a él, como Jacinto Choza. En su escrito «La imaginación del saber», recoge parte de la influencia hegeliana de su amigo Choza y la expone (junto a la de otros autores), mostrando especialmente el punto de vista de Hegel sobre la cultura, y sus coincidencias con el de Choza. Además de este escrito, en 2017 entraría a considerar al espíritu absoluto de Hegel. En su escrito «Arte, religión, filosofía. La doble posible interpretación del Espíritu Absoluto en G. W. F. Hegel», el profesor Hernández-Pacheco consigue dar una interpretación bastante curiosa. La cuestión que trata, como se dice desde el título, es una ambigüedad que existe a la hora de interpretar a Hegel. Arte, religión y filosofía pueden ser realidades que se sustituyen sucesivamente. De esta manera, el arte es deconstruido por la religión, y luego, la religión por la filosofía, generando así una especie de mecanismo de sustitución. Esto daría lugar a una filosofía crítica. Por el contrario, también puede ser una estructura triádica que se co-implica mutuamente, lo que evita esta sustitución. Su conclusión es que los niveles del espíritu absoluto serían imposibles si se reducen sucesivamente. Es más, es deseable que esto no ocurra porque, como comentó

[1] Javier Hernández-Pacheco, «Fe y reflexión. Réplica a Jacinto Choza y Juan Arana», Thémata. Revista de filosofía, 1996, $\mathrm{n}^{\circ}$ 16, $\mathrm{p}$. 
risueñamente, «pensemos por ejemplo en lo insufrible que sería un arte puramente racional para el que todo ornamento fuese delito; o una estética beata para la que lo bello se hiciese fácilmente pecado». ${ }^{2}$

Finalmente, me gustaría remarcar la tarea de Hernández-Pacheco cuando terminó por culminar sus estudios sobre Hegel con su obra Hegel: introducción e interpretación en 2019. A más de un lector creo que nos dejó atónitos la audacia de esta obra. Sin necesidad de citar, ni de utilizar un lenguaje oscuro, Hernández-Pacheco va recorriendo tres obras principales de Hegel, exponiéndolas y explicando su interpretación. Estas son la Fenomenología del Espíritu, la Ciencia de la Lógica y su Enciclopedia de las ciencias filosóficas. Tras esto, trata el problema del saber absoluto, y el libro termina con una propuesta muy propia de Hernández-Pacheco, a la que denomina «Revertir a Hegel» bajo el subtítulo de «de la dialéctica de vuelta a la metafísica, y al revés». En este último capítulo discute intelectualmente con Hegel, y vuelve a defender la irreductibilidad del arte, la religión y la filosofía, de manera en que realiza un llamamiento a la humildad. Ni el arte ni la religión ni la filosofía son sustituibles entre sí, sino que la co-implicación entre sí es lo verdadero, lo real. Esta discusión con Hegel, tal y como sostuvo Hernández-Pacheco, es la manera de ofrecer una nueva interpretación sobre él. Es un legado que quizá haríamos bien en considerar como un futuro que explorar.

No obstante, Hegel es solo uno de los pensadores que influyeron y a los que se dedicó Javier Hernández-Pacheco. Es parte de su horizonte intelectual. Durante largos años espero que la memoria de este catedrático español, ejemplo de precocidad y honestidad intelectual, auténtico filósofo - que no un simple investigador-, permanezca con nosotros como ideal a alcanzar. Como ejemplo de alguien que fue capaz de llegar a donde nadie se atrevía Y especialmente, de alguien que disfrutó siempre en su quehacer filosófico. En definitiva, que siga siendo fuente de inspiración. Como él mismo escribía: «podemos dar de comer a un niño, pero la sonrisa con que nos premia es algo que supera lo que hicimos». ${ }^{3}$ Y esta es la misma sensación con la que nosotros nos quedamos tras su marcha: sabiendo que nos premió con algo que nos supera.

[2] Javier Hernández-Pacheco, «Arte, religión, filosofía. La doble posible interpretación de Espíritu Absoluto en G. W. F. Hegel», Contrastes: revista internacional de filosofia, 2017, Vol. 22, No 3, p. 163.

[3] Javier Hernández-Pacheco, «El cielo. Una reflexión contemporánea». En Infierno y paraíso: el más allá en las tres culturas, 2004, p. 151. 